\title{
Micro-Mechanical Finite Element Analysis of Z-pins under Mixed-Mode Loading
}

\author{
B. Zhang ${ }^{\mathrm{a},{ }^{*}}$, G. Allegri ${ }^{\mathrm{b}}$, M. Yasaee ${ }^{\mathrm{a}}$, S. R. Hallett ${ }^{\mathrm{a}}$ \\ ${ }^{a}$ Advanced Composites Centre for Innovation and Science (ACCIS), \\ University of Bristol, Queen's Building, University Walk, BS8 1TR, Bristol, UK \\ ${ }^{\mathrm{b}}$ Department of Aeronautics, Imperial College London, \\ South Kensington Campus, SW7 2AZ, London, UK
}

\begin{abstract}
This paper presents a three-dimensional micro-mechanical finite element (FE) modelling strategy for predicting the mixed-mode response of single Z-pins inserted in a composite laminate. The modelling approach is based upon a versatile ply-level mesh, which takes into account the significant micromechanical features of Z-pinned laminates. The effect of post-cure cool down is also considered in the approach. The Z-pin/laminate interface is modelled by cohesive elements and frictional contact. The progressive failure of the Z-pin is simulated considering shear-driven internal splitting, accounted for using cohesive elements, and tensile fibre failure, modelled using the Weibull's criterion. The simulation strategy is calibrated and validated via experimental tests performed on single carbon/BMI Z-pins inserted in quasi-isotropic laminate. The effects of the bonding and friction at the Z-pin/laminate interface and the consequences of the internal Z-pin splitting are discussed in detail. The primary aim is to develop a robust numerical tool, as well as guidelines for designing Z-pins with optimal bridging behaviour. .
\end{abstract}

Keywords: B. Delamination; Mechanical properties; C. Finite element analysis (FEA); Z-pinning

*Corresponding author: b.zhang@,bristol.ac.uk (B. Zhang); +44(0) 1173315311 


\section{Introduction}

Z-pinning is a through-thickness reinforcement technique, whereby small diameter continuous rods are inserted through the thickness of composite laminates to increase the "apparent" interlaminar fracture toughness [1]. The adjective "apparent" is used here to denote the fact that the fracture toughness of Zpinned laminates is not an inherent material property, but it depends on the Z-pin configuration used (material, diameter, length and insertion angle), as well as the baseline fracture toughness of the laminate. The Z-pinning technology is based on a relatively simple manufacture process in comparison with other reinforcement techniques such as 3D weaving, stitching and braiding [2]. Extensive experimental investigations have been carried out in order to characterise the delamination suppression mechanisms of Z-pins in composite structures, such as laminated beams under mixed-mode loading and T/L-joints [3-5]. However, given the large number of factors that influence the Z-pin bridging response, exploring the Zpin reinforcement mechanisms by virtual testing, i.e. via the finite element method (FEM), is highly desirable. Throughout the open literature, the modelling of Z-pinned composite structures is based on explicitly representing the single/multiple pin behaviour by bilinear or tri-linear traction-separation laws. These are derived from experiments, simplified FE models or semi-analytical models of single Z-pins [610].

Yasaee et al. [11] presented an experimental characterisation of single T300/BMI carbon Z-pin bridging mechanism in quasi-isotropic IM7/8552 laminates under a range of mode mixities. The bridging abilities of carbon and titanium Z-pins in Mode I pull-out and Mode II shear were compared in [12]. The experimental tests in [13] confirmed that the bridging ability of Z-pins is affected by the failure strength of Z-pin and the microstructure of Z-pinned laminates, including pin misalignment, interfacial debonding around the Z-pin and porosity within the Z-pin.

Several micro-mechanical modelling approaches have been developed to predict the single Z-pin reinforcement mechanisms. Cox $[4,14,15]$ established a comprehensive analytical model for the mixedmode bridging analysis by taking into account the pin actual orientation with respect to the fracture plane and the consequent "snubbing" effect (enhanced friction). In Cox's model, the constitutive equations are derived by assuming that the Z-pin behaves as a linear-elastic/perfect-plastic body; the embedding laminate is described as a perfectly plastic medium. The Cox's model gives the relation between the bridging traction and crack open/sliding displacement in the form of implicit functions. Allegri and Zhang [16] proposed an explicit micro-scale model for the response of single Z-pins. Explicit models, i.e. those 
yielding the bridging tractions as functions of the delamination opening/sliding displacements, are easier to implement in FE analysis. Bianchi and Zhang $[17,18]$ proposed an analytical model, whereby a Z-pin is assumed to behave as an Euler-Bernolli embedded in an elasto-plastic foundation. The resulting forcedisplacement relationship has been employed to predict the response of Z-pinned composite T-joints, as well as Mode II delamination suppression in Z-pinned laminates. Meo et al [19] developed a simplified and efficient FE modelling tool to simulate the pure Mode I pull-out. The Z-pin/laminate interface is modelled by contact elements, and post-debonding pull-out is described by a Coulomb-type friction law with an initial shear stress and a capped maximum frictional stress. Cui proposed a simplified twodimensional FE approach for predicting the mixed-mode response of single Z-pins [20]. Most recently Allegri et al. [21] extended the approach proposed by Bianchi and Zhang $[17,18]$ to the prediction of the mixed-mode bridging response of single Z-pin. This approach gave results in excellent agreement with experiments in terms of traction-displacement response and apparent fracture toughness. However, all the semi-analytical models mentioned above do not consider the post-cure cool-down. Finite element simulations show that thermal residual stresses are responsible for the partial debonding of the Z-pin from the surrounding laminate. This has a strong influence on the consequent pullout behaviour [22]. Furthermore, the modelling approaches discussed so far simplify or even completely ignore the actual microstructural features of Z-pinned laminates, such as the stacking-sequence dependent resin-pocket orientation for each ply and the resulting non-uniform contact along the perimeter of the pin.

Dickinson et al. [21] developed a star-like ply-level FE mesh for estimating the elastic constants of Zpinned composites. This mesh allows describing the microstructure of Z-pinned laminates, including the resin pocket, the fibre waviness surrounding the resin pocket and the pin misalignment. The same meshing architecture is adopted in this study. However, in this paper, the following mechanisms and features are also considered: the post-cure cool down effect; the plastic behaviour of the matrix in the resin pockets; the progressive debonding of the Z-pin/laminate interface; the friction between Z-pins and laminates; the shear-driven splitting within Z-pins and the subsequent progressive tensile fibre failure. All these mechanisms are described in a full three-dimensional fashion.

The modelling approach proposed here can be employed to predict the complete pin pullout/deformation/failure process and the associated bridging forces, as well as the increase of the apparent fracture toughness of Z-pinned laminates. The proposed methodology allows accounting for the stacking 
sequence effect, as well as the geometrical configuration and elastic properties of the through-thickness reinforcement.

\section{Experimental characterisation}

The modelling strategy that will be outlined in Section 3 is calibrated and validated by mechanical tests carried out on single Z-pins subject to mixed-mode loading at the University of Bristol [11]. Thus, the experimental methodology is first introduced here in order to provide a rationale for the modelling development that will follow. Fig. 1 presents the specimen configuration used for the mechanical tests. The coupon consists of a top half-laminate block, a bottom half-laminate block and a single Z-pin. The two half blocks were separated by a PTFE release film on the mid-plane and bridged only by the single Zpin inserted through the thickness of the laminate. The mechanical loads were applied using the modified Arcan jig shown in Fig. 2. The key element of the fixture is the central rotating plate, which comprises a central slot to accommodate the specimen. Adjusting the orientation of the central plate allows varying the mode-mixity ratio. For Mode I and mixed-mode tests, cyanoacrylate superglue (Loctite Corp., UK) was employed to bond the top/bottom sub-laminates to the top/bottom half of the loading jig. This operation was carried out with special care to avoid damaging the Z-pin. Mode II tests were carried out by loading opposite edges of the top and bottom sub-laminates; in this case, no adhesive was required since the opening displacement was constrained, so coupons could not slip out of the jig.

\section{Modelling Method}

This section firstly outlines the general scheme of the modelling method; then it provides detailed explanations of the various steps of the overall simulation procedure.

\subsection{General implementation procedure}

1. A ply-level mesh accounting for the microstructural features of Z-pinned laminates is generated.

2. A full laminate mesh is generated by stacking up the ply-level meshes. Each ply of the laminate comprises at least one layer of the ply-level mesh. The Z-pin misalignment is considered in the mesh.

3. The material properties of the Z-pin, the resin pocket and the surrounding laminate are defined for each ply.

4. The Z-pin/laminate interface is described by cohesive elements which experience progressive 
failure. After the breakage of the interface, the Z-pin/laminate friction is described by a modified Coulomb friction law.

5. Progressive splitting of the through-thickness reinforcement is modelled by inserting cohesive elements within the Z-pin mesh part. The normal to the cohesive elements are aligned with the global mode II shearing direction. Coulomb friction contact is defined between adjacent fibre strands separated by the splits.

6. Prior to the application of delamination loading, a temperature difference field is imposed to the full model, to simulate the effect of post-cure cool down.

7. The boundary condition of the delamination loading was applied according to mode mixity.

\subsection{Ply-level mesh}

As detailed in [23], Z-pinned laminates present different microstructural features in comparison to the unpinned one. The in-plane microstructure of a Z-pinned unidirectional composite is shown in Fig. 3. During Z-pin insertion, the fibres around the Z-pins are pushed aside and bent. After cure, an eyelike elongated resin rich pocket is formed around the Z-pin. In each ply, the elongation of the resin pocket will follow the fibre direction. The laminate region where fibres are distorted by the presence of the Z-pin is assumed to have a rectangular shape. The area of the fibre waviness region, the maximum waviness angle and the area of the resin pocket all increase with the Z-pin diameter.

Regarding the out-of-plane microstructure of a Z-pinned laminate, due to the insertion resistance and resin flow during cure, the insertion angle is always offset from the intended direction $[1,11,24]$. The following features of the out-of-plane microstructure are assumed to have negligible effect on pin reinforcement in current study:

1. The out-of-plane swelling of laminates caused by accommodating Z-pin is ignored. This scenario is significant for high-density Z-pin array reinforcement laminate. Nevertheless, this effect is negligible for single Z-pin coupons.

2. Z-pins are assumed to be cylinders with circular cross-sectional area, with no internal splitting before the cure process and no fibre crimping along the Z-pin length. The standard ultrasound-based Z-pin insertion process may actually induce both Z-pin splitting and out-of-plane fibre crimping [1], but more advanced insertion techniques have been proposed to mitigate these issues $[6,25]$.

Based on the assumptions, the in-plane microstructure of the Z-pinned laminate is described by a star-like ply-level mesh, as shown in Fig. 4a. The ply-level mesh accounts for four possible ply orientations, i.e. $0^{\circ}$, 
$-45^{\circ}, 45^{\circ}$, and $90^{\circ}$, and the associated stacking sequences. For a given stacking sequence, each ply is defined by assigning matrix properties to the resin pocket (red in Fig. 4a) and 3D orthotropic properties to the laminate region (blue in Fig. 4a). The central part of the ply-level mesh represents the Z-pin cross section. The ply local $\mathrm{x}$-axis is in the nominal fibre direction. The global $\mathrm{X}$ axis is aligned with the local $\mathrm{x}$-axis of $0^{\circ}$ plies.

As an example, the mesh definition of $45^{\circ}$ ply is shown in Fig. $4 \mathrm{~b}$. The rectangular fibre waviness region has the length $\mathrm{L}$ and width $\mathrm{W}$. The fibre waviness angle within the region is described in the local coordinate system as

$$
\theta(x, y)=-\theta_{\max } \cdot \frac{4|x|(W-|y|)}{W L} \cdot \operatorname{sgn}(x y)
$$

where the sign function, $\operatorname{sgn}(\bullet)$, ensures the correct waviness angle definitions in the four quadrants associated with the local coordinate system. The maximum fibre waviness angle $\theta_{\max }$ is assumed to occur at two tips of the elongated resin pocket, and given by

$$
\theta_{\max }=\operatorname{atan}\left(\frac{2 b}{L}\right)
$$

where $b$ represents half of the resin pocket width, which is very close to the Z-pin diameter.

For any given ply, Eq. 2 represents the resin pocket profile (resin-pocket/laminate boundary) in the associated local coordinate system. In Eq.2, $\alpha$ is a profile adjusting parameter. The resin pocket becomes narrower when $\alpha$ is decreased.

$$
b \cdot\left(\frac{L}{2}-|x|^{\alpha}\right)-|y|=0
$$

The ply-level mesh is also capable of explicitly representing the Z-pin misalignment. The ply-level mesh with the offset pin can be obtained from that for the straight Z-pin by translating the top surface nodes, to achieve the through-thickness offset $\zeta$ and the in-plane offset $\psi$ angles defined in the X-Y-Z coordinate system, as shown in Fig. 5a. All the parameters used in Eqs. 1-2 as well as the Z-pin misalignment angles can be evaluated from the single Z-pin coupons, via microscopy and/or CT-scans [11,23].

\subsection{Z-pin misalignment definition}

The method for taking Z-pin misalignment (shown in Fig. 5) into account is to directly mesh the FE model with an offset Z-pin. In Fig. 5, the angle $\chi$ between the loading velocity $\mathrm{V}$ and the global $\mathrm{Z}$ axis gives a nominal mode-mixity $(\sin \chi)$. The relative movement between the top half laminate and the bottom 
half laminate is given in Eq. 3 in the global X-Y-Z coordinate system. $\theta$ is the in-plane angle between velocity $\mathrm{V}$ and global $\mathrm{X}$-axis.

$$
\left[\begin{array}{c}
V_{X} \\
V_{Y} \\
V_{Z}
\end{array}\right]=\left[\begin{array}{c}
V \sin \chi \cos \theta \\
V \sin \chi \sin \theta \\
-V \cos \chi
\end{array}\right]
$$

The actual mode-mixity is defined as the ratio of the delamination sliding velocity (displacement) to the total velocity (displacement). To derive the actual mode-mixity for the direct method, the local Z-pin coordinate system $X_{\text {pin }}-Y_{\text {pin }}-Z_{\text {pin }}$ as shown in Fig. 5 is introduced. The $Z_{\text {pin }}$ axis is directed opposite to the global $\mathrm{Z}$ axis. The $\mathrm{Y}_{\text {pin }}$ axis stays in the global $\mathrm{X}-\mathrm{Y}$ plane and it is obtained by the rotation angle $\phi$ with respect to the global $\mathrm{Y}$ axis. The positive direction of the $\mathrm{X}_{\text {pin }}$ axis is derived by the right-hand rule. Then, the relative velocity between the top half pin and bottom half pin at the fracture plane can be resolved in the local Z-pin coordinate system by Eq. 4.

$$
\left[\begin{array}{l}
V_{X_{p i n}} \\
V_{Y_{\text {pin }}} \\
V_{Z_{\text {pin }}}
\end{array}\right]=\left[\begin{array}{ccc}
-\cos \zeta \cos \psi & -\cos \zeta \sin \psi & \sin \zeta \\
\sin \psi & -\cos \psi & 0 \\
-\sin \zeta \cos \psi & -\sin \zeta \sin \psi & -\cos \zeta
\end{array}\right]\left[\begin{array}{c}
-V \sin \chi \cos \theta \\
-V \sin \chi \sin \theta \\
-V \cos \chi
\end{array}\right]
$$

Consequently, for the direct method of defining Z-pin misalignment, the mode mixity $\phi$ is derived by: $\phi=\frac{\sqrt{V_{X_{\text {pin }}}{ }^{2}+V_{Y_{\text {pin }}}{ }^{2}}}{\sqrt{V_{X_{\text {pin }}}{ }^{2}+V_{Y_{\text {pin }}}{ }^{2}+V_{Z_{\text {pin }}}{ }^{2}}}=\sqrt{\cos ^{2} \chi \cos ^{2} \zeta+\sin ^{2} \chi\left(\sin ^{2} \psi+\cos ^{2} \psi \cos ^{2} \zeta\right)-1 / 2 \sin 2 \chi \sin 2 \zeta \cos \psi}$ (5) Therefore, in order to obtain the actual mode-mixity for a single Z-pin, the pull-out angle $\chi$ can be obtained from Eq. 5. Then the corresponding boundary condition in the X-Y-Z coordinate system can be defined according to Eq. 3. As shown in Eq. 6, the actual mixed-mode angle $\omega$ can be equivalently expressed in terms of either the actual mode mixity or velocity components.

$$
\omega=\tan ^{-1}\left(\frac{\emptyset}{\sqrt{1-\emptyset^{2}}}\right)
$$

\subsection{Z-pin/laminate interface definition}

From the tests in [11], the Z-pin bridging force is governed by the interface bonding and friction between the Z-pin and surrounding laminate. In the current modelling strategy, the interface is described by cohesive elements, which, upon failure, are replaced by a contact interaction defined by a modified Coulomb friction law. Specifically, the interface bonding is described by zero-thickness cohesive elements inserted between the Z-pin and the laminate. The failure criterion of the interface cohesive elements is evaluated by a quadratic stress criterion given by [26]:

$$
\left(\frac{\max \left(\sigma_{I}, 0\right)}{\sigma_{I, \max }}\right)^{2}+\left(\frac{\sigma_{I I}}{\sigma_{I I, \max }}\right)^{2}=1
$$


where $\sigma$ indicates the element stress; $\sigma_{\max }$ as the element strength and Roman numerals I and II indicate Mode I and Mode II loadings respectively. The failure evolution is evaluated by a power law criterion expressed by [26]:

$$
\left(\frac{G_{I}}{G_{I C}}\right)^{\beta}+\left(\frac{G_{I I}}{G_{I I C}}\right)^{\beta}=1
$$

where $G$ as the strain energy release rate; $G_{C}$ as the critical strain energy release rate and $\beta$ as the power of the failure evolution criterion.

The actual geometry of the contact surface between the Z-pin and the laminate in the coupons has large geometrical irregularities and roughness, which is difficult to describe explicitly in the FE mesh. For this reason the interface friction will need to be artificially increased in the FE model to account for this effect. This is done by adding a residual friction stress $\tau_{0}$ on top of the "standard" Coulomb friction. Consequently, as show in Eq. 8a, the friction law used in the current modelling strategy defines the friction between the Z-pin and the laminate as the sum of the contribution due to the residual shear stresses plus a term given by the standard Coulomb friction law. Eq. $8 \mathrm{~b}$ shows the normal stress used to calculate the frictional shear stress in the FE analysis.

$$
\begin{gathered}
\tau_{t}=\max \left(\tau_{\max }, \tau_{0}+\mu \sigma_{n}\right) \\
\sigma_{n}=k \cdot \max (d, 0)
\end{gathered}
$$

In Eqs. 8a-b, $d$ represents the interpenetration depth of the contact surfaces. $\sigma_{\mathrm{n}}$ is the normal stress due to the penetration; $\mathrm{k}$ is the penalty stiffness of contact in the FE model; $\tau_{\mathrm{t}}$ is the shear stress due to friction; $\tau_{\max }$ is the maximum allowed shear stress, respectively. Finally, $\mu$ is the Coulomb friction coefficient.

\subsection{Z-pin splitting definition}

Commercial Z-pins are manufactured via pultrusion of uni-directional carbon fibre tows impregnated with bismaleimide (BMI) resin [1]. If a Z-pin is subjected to high longitudinal-transverse shear stresses it is susceptible to split into strands that can slide relative to each other and accommodate further loading before failure [14]. In the present modelling method, columns of zero-thickness cohesive elements with their normal direction oriented in the Mode II loading direction are inserted in the Z-pin at potential splitting locations. In other words, the Z-pin splitting is assumed to occur only in the planes normal to the Mode II shear loading direction. As an example, the Z-pin mesh with 11 layers of splitting elements is shown in Fig. 6. The angle between the normal direction of split elements and global X-axis is $\kappa$. These splitting elements also follow the criterions defined in Eqs. 7a-b. Once these cohesive elements fail, the exposed surfaces will experience standard Coulomb friction contact, with maximum frictional stress 
capped at a characteristic value. Note that for the monolithic Z-pins such as the metal ones [12], it is not necessary to model the splitting process.

\section{Case study for method validation}

In order to demonstrate the accuracy of the modelling strategy proposed here, the reinforcement micromechanics of T300/BMI carbon fibre Z-pins inserted in the IM7/8552 composite laminate is investigated.

\subsection{Full mesh generation}

The model definition refers to the experiment set-up in [11]. Specifically, the specimen consists of two blocks, each of which comprises 32 IM7/8552 plies (Hexcel, UK). The nominal thickness of each ply is $0.125 \mathrm{~mm}$, with a stacking sequence of $\left[(0 / 45 / 90 /-45)_{4 \mathrm{~s}} / /(90 /-45 / 0 / 45)_{4 \mathrm{~s}}\right]$ and nominal Z-pin diameter of $0.28 \mathrm{~mm}$. Tab. 1 lists the parameters defining the ply level mesh [23]. Each one of the middle 24 plies consists of four layers of ply-level meshes, in order to accurately describe the enhanced friction zone near the fracture plane. There are 136 layers of ply-level meshes in the full model, as shown in Fig. 7. The models are created and computed by commercial FE package Abaqus/Explicit. There are 351568 eightnode brick elements, 4640 six-node wedge elements, 4608 Z-pin/laminate interface elements, 15768 splitting elements and 386864 nodes in the model. A $0.0625 \mathrm{~mm}$ (half ply thickness) gap is introduced between the two laminate blocks, to avoid potential issues associated with high element distortion on the interlaminar fracture plane. The gap size has minor effect on the Z-pin bridging performance if it is below one ply thickness [20].

\subsection{Material definition}

Linear-elastic orthotropic material properties are employed to model both the laminate and the Z-pin. The neat resin is modelled as an isotropic elasto/perfectly plastic material, with yield occurring at 90Mpa [28]. The associated properties defined in the local coordinate system x-y-z of each ply are listed in Tab. 2 [2931]. The thermal expansion coefficients for the Z-pin are assumed to be same as those for the laminate.

The Z-pin strength is described using a classical two-parameter Weibull's failure criterion [32], which is based upon the assumption that only axial tension stresses govern the Z-pin failure [11]. The twoparameter Weibull's failure criterion states that the probability of survival under a stress field is

$$
P(s)=\exp \left[-\int\left(\frac{s}{s_{0}}\right)^{m}\right]
$$


where $s_{0}$ is the characteristic strength (or scale parameter) and $m$ is the Weibull modulus (or shape parameter). Using the assumption of equal probability of survival for individual volumes within the Z-pin and an ASTM standard tensile test [33], one finds

$$
\exp \left[-V_{E}\left(\frac{s_{E}}{s_{0}}\right)^{m}\right]=\exp \left[-V_{A S T M}\left(\frac{s_{A S T M}}{s_{0}}\right)^{m}\right]
$$

where $\mathrm{V}_{\mathrm{E}}$ is the volume of individual element; $S_{E}$ is the fibre-direction tensile stress in the element. $V_{A S T M}$ is the volume of standard ASTM sample, i.e. $3750 \mathrm{~mm}^{3} . s_{A S T M}$ is the unidirectional failure stress of standard ASTM sample, i.e. $1860 \mathrm{Mpa} ; m$ is assumed to be 31 . From Eq. 9 b, it is straightforward to derive the following strength scaling criterion

$$
\frac{V_{E}}{V_{A S T M}}\left(\frac{s_{E}}{s_{A S T M}}\right)^{m}=1
$$

\subsection{Boundary condition definition}

Six groups of experiments with nominal mode mixities ranging from pure Mode I to pure Mode II are employed to validate the present modelling method [11]. Each group comprises more than three specimens. The loading method in the FE models is the same as in experiments. The average experimental value of the Z-pin misalignment for each group is used in the FE model.

\subsection{Z-pin splitting and Z-pin/laminate interface definition}

The Z-pin mesh with 11 layers of splitting cohesive elements, as shown in Fig. 6, is employed in this case study. Since the Mode II shear deformation is applied along the global X axis, the normal of the split elements follows the global X-axis. It implies that $\kappa$ is equal to $0^{\circ}$ in Fig. 6 . The modelling parameters for the Z-pin splitting and the Z-pin/laminate interface are listed in Tab. 3, whereby $\mathrm{K}$ is the cohesive element stiffness prior to damage initiation. The exact values used for the cohesive elements are not critical, since they show varieties amongst samples. All the cohesive element definition refers to the interlaminar bonding modelling parameters [29], whereas much lower $\mathrm{G}_{\mathrm{IC}}$ value is assigned to the interface cohesive elements, in order to take into account the effect of pin insertion on the interface. In addition, following the failure of the cohesive elements, the parameters of the friction between the split Zpin strands and between the Z-pin and laminate are also given in Tab. 3 [34]. The maximum allowed frictional stress $\left(\tau_{\max }\right)$ in the interface corresponds to the yield strength of the laminate matrix. To consider more fibre strands may split and subsequently come into frictional contact, a larger $\tau_{\max }$ value is selected for friction between the split strands of the Z-pin modelled by 11 potential split layers in Fig. 6 . 


\subsection{Post-cure cool down step}

Prior to the mechanical loading, a $-160{ }^{\circ} \mathrm{C}$ temperature differential is imposed to the full model, to simulate the effect of post-cure cool down on the Z-pinned laminate.

\section{Results and discussions}

\subsection{Post-cure cool down results}

The post-cure cool down process will have a strong influence on the residual bond strength of the Zpin/laminate interface, which affects the bridging performance of the Z-pin. FE results indicate that the interface is loaded predominantly in its radial direction. Fig. 8a depicts the thickness-direction stress of the interface at $-50^{\circ} \mathrm{C}$ cool down. The maximum stress for each ply appears in the interface segments that are facing the resin pocket along its longitudinal direction, i.e., the local $x$ axis direction. With further thermal loading, the interface debonding initiates along a helix path, due to the stacking sequence considered in this case. The interface conditions at $-100^{\circ} \mathrm{C}$ and $-160^{\circ} \mathrm{C}$ cool down are described respectively by the cohesive element failure indicator in Figs. 8b-c. The interface toughness is degraded gradually when the indicator increases from 0 to 1 . Fig. $8 \mathrm{~b}$ shows that the interface failure initiates from the fracture plane and the Z-pin ends. Fig. 8c indicates that the interface has been largely weakened and partially failed at the end of the thermal step. This result is in agreement with what found in $[6,22]$. As it will be discussed in next section, the weakening of the interface, is responsible for the absence of a load drop that would otherwise mark a debonding primarily driven by mechanical loading. Hence, the interface friction dominates the bridging load. This conclusion is confirmed by the experiments, whereby $80 \%$ of the samples with Z-pin pull-out showed no early-stage load drop that could be attributed to debonding. The effect of interface bonding toughness on the Z-pin bridging performance will be discussed in detail in Section 5.4.

\subsection{Bridging mechanisms}

It was not possible to manufacture a perfectly orthogonal Z-pin, thus all the six cases are actually mixed Mode I/II loadings, Figs. 9a-b show the snapshot comparison between Z-pins bridging the two laminate blocks against the mixed-mode loading in the FE model and experiment. The Z-pin acts as a throughthickness reinforcement element through suppressing the opening (Mode I) and sliding (Mode II) between two half laminate blocks. As explained in Section 5.1, the interface is significantly weakened after the cure step. The result is that the opening is suppressed mainly by the interface friction between Z- 
pin and laminate. Eq. 8a indicates that one source of the friction is the residual friction stress $\tau_{0}$, while the other one is the standard Coulomb friction. The FE analysis shows that the Coulomb friction term is mainly attributed to the enhanced friction zone near the fracture surface, as indicated in the partial enlarged viewport in Fig. 9c. The enhanced friction zone occurs because of the presence of constitutive Mode II shear in the mixed-mode loading. Therefore, it can be summarised that the Z-pin suppresses the opening of two blocks through the combination of the residual friction on the inserted Z-pin surface and the enhanced friction in the enhanced friction zone.

The Z-pin resists the Mode II shear sliding between two laminate blocks through experiencing the 'S' shape deformation. The Z-pin deformation causes the enhanced friction zone, as aforementioned above whilst the maximum tensile stress forms directly opposite to it in each half of the Z-pin, as shown in Fig. 9c. The maximum tensile stress increases with the mixed-mode ratio and friction, until Z-pin rupture initiates when the failure criterion defined in Eq. 9c is satisfied. In addition, the ' $S$ ' shape deformation of the Z-pin also results in large axial shear stresses within the Z-pin, as shown in Fig. 9c. FE results show that the maximum shear stress always falls between the maximum tensile region and the enhanced friction zone in each half of the Z-pin, and moves by following the Z-pin pull-out.

The large shear stress will cause the splitting scenario within the Z-pin, which is confirmed by the comparison between experiment observation and FE simulation under 0.985 mode-mixity loading, as shown in Fig. 10a. FE results indicate that the Z-pin splitting initiates from its neutral plane at around 0.7 mode mixity. The normal of the neutral plane is in the direction of the Mode II loading. Under the further loading, the splitting propagates along both the neutral plane and the fracture plane. Because the mixedmode ratio at which the splitting happens is quite large, complete pin rupture dominates the Z-pin failure mode. Fig. 10b illustrate the complete Z-pin rupture observed in experiments and FE models under 0.819 mode-mixity loading. It can be seen that the Z-pin splitting has already happened before the pin rupture. Due to the asymmetry of the Z-pins and laminates, the failure always takes place from one side of the Zpin.

\subsection{Bridging results}

For the validation of this modelling method, the load versus displacement curves for all the six mode mixities are compared with the experimental results in Figs. 11a-f. For all the mode mixities, the bridging force increases initially with a large stiffness, which is due to the residual stress $\tau_{0}$. With further loading, the bridging force continues increasing, but with a reduced slope. Apart from the residual stress, this part 
of bridging force is also attributed to the enhanced friction zone and Mode II shear loading exerted by the deformed Z-pin. With further loading, the load vs. displacement trend strongly depends on the mode mixity.

In the mode-mixity region with complete pin pull-out (i.e. mode-mixity values below 0.5 ) shown in Figs. $11 \mathrm{a}-\mathrm{b}$, both FE models and experiments show the bridging force rises up to the peak value and then decreases gradually until complete pull-out of the Z-pin. The peak force increases with the mode mixity, since both the forces due to the enhanced friction zone and Mode II shear bridging increase with the mode mixity.

On the other hand, Figs. 11d-f demonstrate that for the mode-mixity region with complete pin rupture (i.e. mode-mixity values in excess of 0.8 ), the bridging forces increase until the first pin strand failure happens in one side of the maximum tensile zones shown in Fig. 9c. The failure stress of the first strand is around 3350MPa. Due to the asymmetry of the experimental samples, the Z-pin failure located only in one side of the maximum tensile regions. After the first strand failure, the remaining strands of pin fibres are capable of withstanding the further loading. The Z-pins experience progressive strand failure until complete breakage. The failure loads of the first Z-pin strand and the complete Z-pin rupture both increase with the mode mixity, while the corresponding displacements decrease with the mode mixity. This implies that for the largest mixed-mode ratio loading in Fig. 11f, the Z-pins should be ruptured with little pull-out of the pin. For the confirmation, the ruptured Z-pins in FE model and experiments are compared in Figs. 12a-b.

For the intermediate region between 0.5 and 0.8 mode mixities, experimental results show scatter on the Z-pin failure mode. The reason behind the scatter is the dependence of Z-pin failure mode on not only the mode mixity, but also other features. This will be discussed in more detail in the next section. The FE results show clear transition from the complete pull-out response and the complete rupture response. In the transition region, Z-pin can be pulled out, but with the rupture of partial strands. The clear transition in the FE results is the result of considering only a single variable (mode-mixity) in the simulations. An example of the variability of the Z-pin response in the transition region can be seen in the experimental load curves of Fig. 11c, where 4 of 5 Z-pins exhibited complete pull-out in the experiments, while the Zpin in the FE model was pulled out with only a single strand failure.

The integration area under the load versus displacement curve is the energy $\left(G_{\text {pin }}\right)$ dissipated by Z-pin during bridging against delamination. For a laminate reinforced by the areal density ( $\rho$ ) of Z-pins, the 
increased resistance to delamination by Z-pinning is evaluated by the apparent fracture toughness $G^{*}(\phi)$ [34]. This $\mathrm{G}^{*}(\phi)$ can be calculated by Eq. 10. All the fracture toughness data given in this study is for $2 \%$ Z-pin reinforcement.

$$
G^{*}(\phi)=\frac{4 \rho}{\pi D^{2}} G_{\text {pin }}
$$

The calculated apparent fracture toughness are compared between FE simulations and experiments in Fig. 13. All the fracture toughness calculated by FE models fall within the limits defined by the average toughness and standard deviation of experimental results. In the complete pull-out region, the apparent fracture toughness increases with the mode mixity. In the complete rupture region, Z-pin breakage causes the large drop in the apparent fracture toughness. Overall excellent agreement is achieved between FE models and experiments in these two regions. As explained earlier, in the transition region between 0.5 and 0.8 mode mixities, scatter is present for the fracture toughness results of experiments, while the FE results show a clear transition.

\subsection{Explanations of scatter on pin bridging based on parametric study}

The excellent agreements between FE and experiments both on bridging forces and apparent fracture toughness have verified the validation of the present modelling method proposed for single Z-pin micromechanical analysis. However, scatter is shown on bridging forces and fracture roughness in the experiments for a given mode mixity, even if the Z-pin misalignment is taken into account. Furthermore, the Z-pin failure mode, i.e., pull-out or rupture, shows large scatter in the pin pull-out/rupture transition region. These scatter scenarios illustrate that apart from the mode mixity, the Z-pin bridging ability is also affected by other factors. These factors mainly comprise the laminate stacking sequence, the Z-pin misalignment, the material properties and geometries of the Z-pin and the laminate, the Z-pin splitting, the Z-pin/laminate interface friction and the Z-pin/laminate interface bonding. The effects of the laminate stacking sequence, the Z-pin misalignment, the material properties and geometries of the Z-pin and the laminate have been investigated in relevant literature $[11,12,15,34,35]$. These remaining three factors are successively discussed in detail as follows, based on parametric study. All other modelling parameters used for the parametric study are identical to the models described in the Section 4. Z-pins are inserted perpendicularly to the laminate in this study.

\section{Effect of the Z-pin Splitting}

The bridging abilities of Z-pins with 0,3, 7, 11 and 15 layers of splitting elements are evaluated. For each splitting density, the full range of mode mixity from 0 to 1 with the increment of 0.1 were calculated by 
the present FE modelling method. The apparent fracture toughness versus mode mixity curves of these six splitting-density Z-pins are compared in Fig. 14. It is clear to identify that the pull-out/rupture transition region is shifted towards higher mode mixity with the increasing number of splitting layers. In other words, Z-pins with lower splitting density demonstrate a more brittle behaviour while Z-pins with higher splitting density offer a more ductile behaviour. This is attributed to the mechanism that the axial tensile stress of the Z-pin is degraded due to the presence of the splitting [15].

Z-pins with a lower splitting density show a larger flexural modulus than Z-pins with a higher splitting density. This means that the former will provide larger bridging force peaks than the latter in the complete pull-out region, and thus the former can provide larger apparent fracture toughness, as shown in Fig. 14. However, in the complete rupture region, even though the lower splitting-density Z-pins can provide a larger bridging forces than the higher splitting-density Z-pins, the latter offer larger apparent fracture toughness than the former, due to larger Z-pin deformations sustained.

Another evident observation from Fig. 14 is that the range of the pull-out/rupture transition region increases with the increasing number of splitting layers, which can be confirmed by the curves of from 0 layer to 11 layers. However, the range does not increase above 11 layers as the transition region has shifted close to pure Mode II loading.

\section{Effect of Z-pin/laminate interface friction}

The dependence of apparent fracture toughness on the residual friction stress $\tau_{0}$ is illustrated in Fig. 15 . The pull-out/rupture transition region shifts towards the lower mode mixities with the increase of $\tau_{0}$. High $\tau_{0}$ value enhances the Z-pin bridging abilities in complete pull-out region, but has negligible effects in the complete rupture region.

The Coulomb component of the interface friction is dominant in the enhanced friction zone, as shown in Fig. 9c. The area of the enhanced friction zone is only dependent on the mode mixity, thus the friction coefficient $\mu$ dominates the Coulomb friction for a given mode-mixity. The FE results also show that the increase of $\mu$ causes the Z-pin pull-out/transition region to shift towards the lower mode mixities, whereas the effect is limited by the allowable maximum frictional stress $\tau_{\max }$. The apparent fracture toughness increases with $\mu$ when the Z-pin can be completely pulled out, although the increasing trend is also limited by $\tau_{\max }$. Additionally, the parameter $\mu$ also has minor effects in the complete rupture region.

\section{Effect of Z-pin/laminate interface bonding}

Similar to the interface friction, the interface bonding toughness will also increase the Z-pin bridging 
performance in complete pull-out region with negligible influence in the complete rupture region. However, the pull-out/rupture transition region is shifted towards the lower mode mixities with the increase of the interface bonding toughness.

In addition, the effect of the interface bonding toughness in the pull-out dominated region can be further illustrated by its contribution to the Z-pin bridging ability under pure Mode I pull-out. Fig. 16 depicts the contributions by varying the $\mathrm{G}_{\mathrm{I}}$ value from zero to $0.1 \mathrm{~N} / \mathrm{mm}$ and $\mathrm{G}_{\mathrm{II}}$ value from 0.2 to $1.0 \mathrm{~N} / \mathrm{mm}$. It can be seen that when the $G_{I I}$ value is lower than $0.2 \mathrm{~N} / \mathrm{mm}$, the bridging energy increases linearly with the $G_{I}$ value. This is because the majority of the toughness is contributed from $\mathrm{G}_{\mathrm{I}}$ for coupons with low $\mathrm{G}_{\mathrm{II}}$ values. For the $\mathrm{G}_{\mathrm{II}}$ values over $0.4 \mathrm{~N} / \mathrm{mm}$, the toughness increases almost linearly with $\mathrm{G}_{\mathrm{I}}$ up to $0.04 \mathrm{~N} / \mathrm{mm}$, and then the increasing rate decreases gradually. In the combination of Fig. 13 and Fig. 16, it can be concluded that the contribution from the interface debonding to the apparent fracture toughness is more than one-order lower than that from interface friction in the complete pin pull-out region.

\section{Remarks}

The results of the parametric study presented in previous sections point out that it is in principle possible to tailor the bridging response of individual Z-pins in order to maximise the enhancement of apparent fracture toughness. To do this, simultaneous modification to the Z-pin/laminate interface and the Z-pin constituents and geometry is necessary. More in detail, if the Coulomb friction coefficient alone is raised by a surface treatment of the Z-pin, there will be an increase of apparent fracture toughness in pull-out dominated region, but also a tendency towards premature failure. Making the Z-pin more compliant, e.g. hybridising glass fibre with carbon in order to reduce the Young's modulus of the through-thickness reinforcement, can counteract the tendency to premature failure. An alternative may be represented by manufacturing Z-pins that are consolidated by less tough resin matrix materials, in order to promote splitting thus generating an apparent ductile response. These various strategies for balancing the toughness enhancement across the whole-mixity range can be assessed using the modelling framework presented in this paper.

\section{Conclusions}

This paper has addressed the development of a three-dimensional FE modelling method for Z-pinned composite laminates. This high-fidelity approach has been successfully employed to analyse the micro- 
mechanical bridging mechanisms of Z-pins under mixed-mode loading. The simulation strategy was based upon a versatile ply-level mesh, which explicitly describes the most significant microstructural features of Z-pinned laminates, including the presence of resin pockets, of fibre waviness surrounding the resin pocket and the Z-pin misalignment. The Z-pin/laminate interface was modelled using cohesive elements. Following the interface debonding, the interface friction was described by a modified Coulomb friction law, which takes the residual friction stress into account. Furthermore, the Z-pin splitting was also modelled using cohesive elements with associated standard Coulomb friction. Additionally, the effect of post-cure cool down is also included in present modelling method.

For the validation of this modelling method, the bridging abilities of $0.28 \mathrm{~mm}$ diameter and $8 \mathrm{~mm}$ length Z-pins (T300/BMI) inserted in the quasi-isotropic laminates (IM7/8552) were computed under the mixedmode loadings. The modelling approach gives results in excellent agreement with experiments in terms of both bridging forces and apparent fracture toughness. FE results indicate that when the mixed-mode ratio exceeds approximately 0.7, Z-pin splitting initiates from the neutral plane and then propagates along the neutral plane and the fracture plane under further loading. In addition, large data scatter in the experiments indicates that the bridging performance of Z-pins is not only dependent on the mode mixity, but also on other factors. With the present modelling method, the Z-pin splitting, Z-pin/laminate interface friction and Z-pin/laminate interface debonding were discussed in detail and their effects on the Z-pin bridging ability pointed out. The modelling methodology described in this paper is suitable for optimising the Z-pin configuration in order to maximise the apparent toughness of through-thickness reinforced laminates.

The present modelling method can be readily extended to Z-pinned laminates with arbitrary configurations in terms of the laminate stacking sequence, the laminate material and the geometry of the Z-pin. The results obtained regarding bridging forces and apparent fracture toughness can be directly employed for predicting the reinforcement performance of Z-pin arrays.

\section{Acknowledgements}

The authors would like to acknowledge Rolls-Royce plc for the support of this research through the Composites University Technology Centre (UTC) at the University of Bristol, UK. 


\section{References}

[1] Mouritz AP. Review of z-pinned composite laminates. Compos Part A Appl Sci Manuf 2007;38:2383-97.

[2] Partridge IK, Cartié DDR, Bonnington T. Manufacture and performance of Z-pinned composites. In: Shonaike, G. O. and Advani SG, editor. Adv. Polym. Mater., CRC Press LLC, USA; 2003, p. 103-37.

[3] Cartié DDR, Troulis M, Partridge IK. Delamination of Z-pinned carbon fibre reinforced laminates. Compos Sci Technol 2006;66:855-61.

[4] Rugg KL, Cox BN, Massabo R. Mixed mode delamination of polymer composite laminates reinforced through the thickness by z-fibers 2002;33:177-90.

[5] Toral Vazquez J, Castanié B, Barrau J-J, Swiergiel N. Multi-level analysis of low-cost Z-pinned composite joints Part 2: Joint behaviour. Compos Part A Appl Sci Manuf 2011;42:2082-92.

[6] Toral Vazquez J, Castanié B, Barrau J-J, Swiergiel N. Multi-level analysis of low-cost Z-pinned composite joints Part 1: Single Z-pin behaviour. Compos Part A Appl Sci Manuf 2011;42:207081.

[7] Bianchi F, Zhang X. A cohesive zone model for predicting delamination suppression in z-pinned laminates. Compos Sci Technol 2011;71:1898-907.

[8] Dantuluri V, Maiti S, Geubelle PH, Patel R, Kilic H. Cohesive modeling of delamination in Z-pin reinforced composite laminates. Compos Sci Technol 2006.

[9] Grassi M, Zhang X. Finite element analyses of mode I interlaminar delamination in z-fibre reinforced composite laminates. Compos Sci Technol 2003;63:1815-32.

[10] Yan W, Liu H-Y, Mai Y-W. Mode II delamination toughness of z-pinned laminates. Compos Sci Technol 2004;64:1937-45.

[11] Yasaee M, Lander JK, Allegri G, Hallett SR. Experimental characterisation of mixed mode traction-displacement relationships for a single carbon composite Z-pin. Compos Sci Technol 2014;94:123-31.

[12] Cartié DDR, Cox BN, Fleck NA. Mechanisms of crack bridging by composite and metallic rods. Compos Part A Appl Sci Manuf 2004;35:1325-36.

[13] Mouritz AP, Koh TM. Re-evaluation of mode I bridging traction modelling for z-pinned laminates based on experimental analysis. Compos Part B Eng 2014;56:797-807.

[14] Cox BN. Constitutive model for a fiber tow bridging a delamination crack. Mech Compos Mater Struct 1999;6:117-38.

[15] Cox BN. Snubbing effects in the pullout of a fibrous rod from a laminate. Mech Adv Mater Struct 2005;12:85-98.

[16] Allegri G, Zhang X. On the delamination and debond suppression in structural joints by Z-fibre pinning. Compos Part A Appl Sci Manuf 2007;38:1107-15.

[17] Bianchi F, Zhang X. Predicting mode-II delamination suppression in z-pinned laminates. Compos Sci Technol 2012;72:924-32. 
[18] Bianchi F, Koh TM, Zhang X, Partridge IK, Mouritz a. P. Finite element modelling of z-pinned composite T-joints. Compos Sci Technol 2012;73:48-56.

[19] Meo M, Achard F, Grassi M. Finite element modelling of bridging micro-mechanics in throughthickness reinforced composite laminates. Compos Struct 2005;71:383-7.

[20] Cui H, Li Y, Koussios S, Zu L, Beukers A. Bridging micromechanisms of Z-pin in mixed mode delamination. Compos Struct 2011;93:2685-95.

[21] Dickinson LC, Farley GL, Hinders MK. Prediction of effective three-dimensional elastic constants of translaminar reinforced composites. J Compos Mater 1999;33:1002-29.

[22] Sweeting RD, Thomson RS. The effect of thermal mismatch on Z-pinned laminated composite structures. Compos Struct 2004;66:189-95.

[23] Chang P. The mechanical properties and failure mechanisms of z-pinned composites. RMIT University, 2006.

[24] Lander JK. Designing with z-pins: locally reinforced composite structures. Cranfield University, 2008.

[25] Johnson DW, Garrett SA, Hook JM, Moyers SG. Method of inserting Z-axis reinforcing fibers into a composite laminate. US 20050006023 A1, 2005.

[26] Harper PW, Hallett SR. Cohesive zone length in numerical simulations of composite delamination. Eng Fract Mech 2008;75:4774-92.

[27] Partridge IK, Cartié DDR. Delamination resistant laminates by Z-Fiber ${ }^{\circledR}$ pinning: Part I manufacture and fracture performance. Compos Part A Appl Sci Manuf 2005;36:55-64.

[28] Marlett K, Ng Y, Tomblin J. Hexcel 8552 AS4 unidirectional prepreg at 190 gsm \& 35 \% RC qualification material property data report. 2011.

[29] Hallett SR, Green BG, Jiang WG, Wisnom MR. An experimental and numerical investigation into the damage mechanisms in notched composites. Compos Part A Appl Sci Manuf 2009;40:613-24.

[30] Grassi M, Zhang X, Meo M. Prediction of stiffness and stresses in z-fibre reinforced composite laminates. Compos Part A Appl Sci Manuf 2002;33:1653-64.

[31] Kueh A, Pellegrino S. Thermo-elastic behaviour of single ply triaxial woven fabric composites. 47th AIAA/ASME/ASCE/AHS/ASC Struct. Struct. Dyn. Mater. Conf., Reston, Virigina: American Institute of Aeronautics and Astronautics; 2006, p. 3726-37.

[32] Li X, Hallett SR, Wisnom MR. A finite element based statistical model for progressive tensile fibre failure in composite laminates. Compos Part B Eng 2013;45:433-9.

[33] D3039/D3039M-08 Standard test method for tensile properties of polymer matrix composite materials. ASTM Int 101520/D3039_D3039M-08 2008.

[34] Allegri G, Yasaee M, Partridge IK, Hallett SR. A novel model of delamination bridging via Zpins in composite laminates. Int J Solids Struct 2014;51:3314-32.

[35] Mouritz AP, Cox BN. A mechanistic interpretation of the comparative in-plane mechanical properties of 3D woven, stitched and pinned composites. Compos Part A Appl Sci Manuf 2010;41:709-28. 


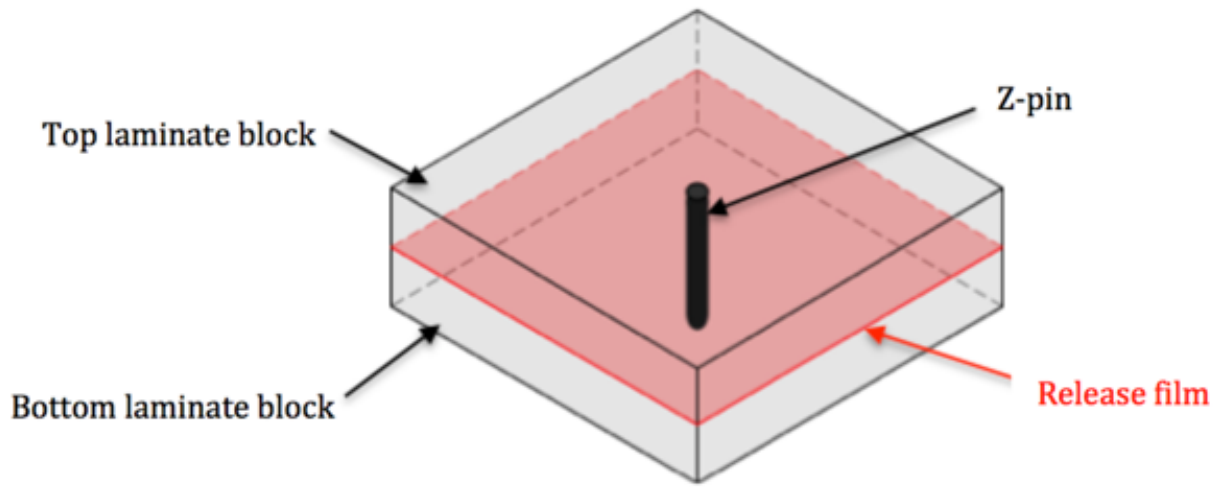

Fig. 1. Schematics of specimen for single Z-pin testing.



(a)

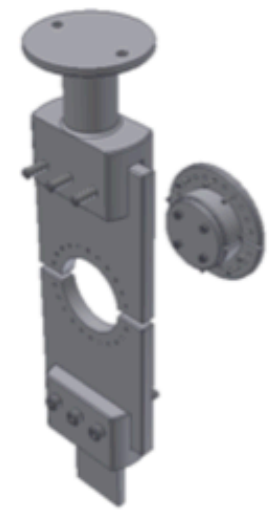

(b)

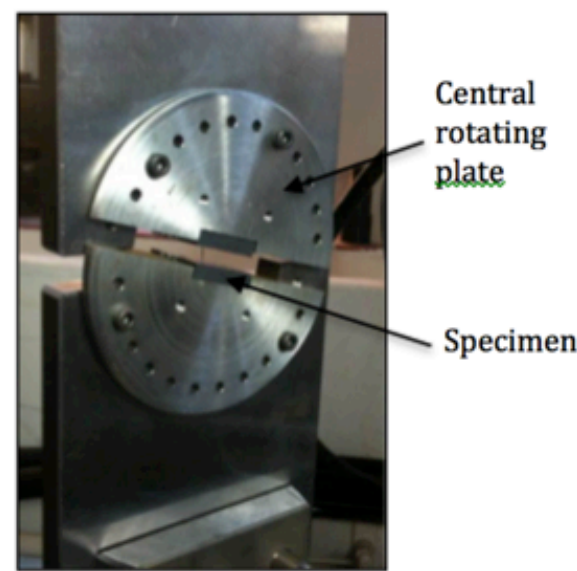

(c)

Fig. 2. Fixture for mixed-mode loading of single Z-pins; (a) front view; (b) back view; and (c) set-up during testing. 


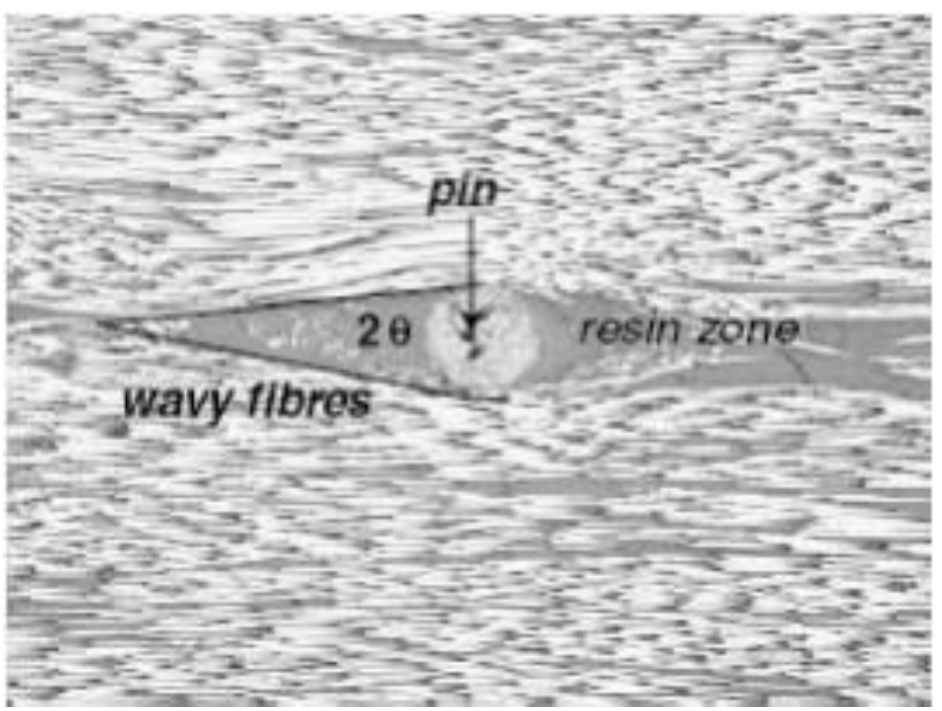

Fig. 3. In-plane microstructure of the Z-pinned laminate [1].

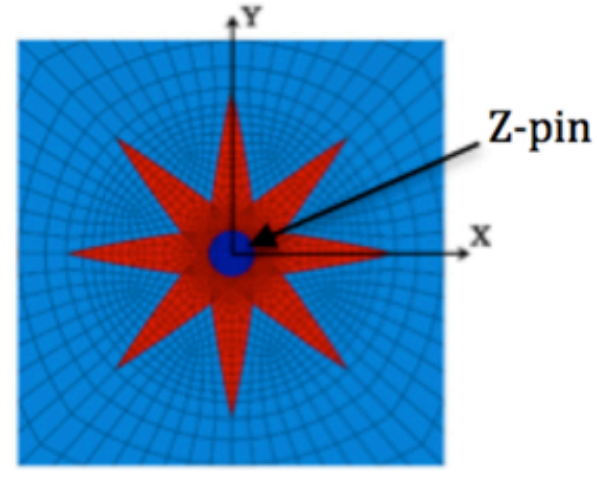

(a)

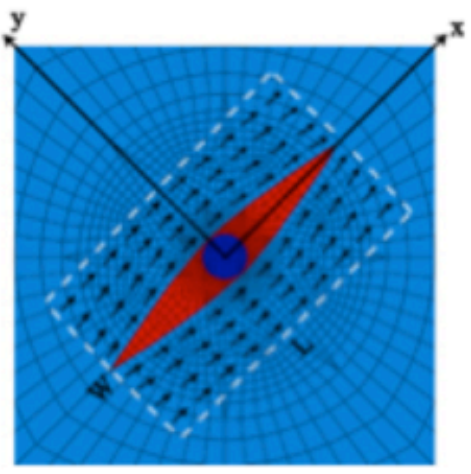

(b)

Fig. 4. Ply-level mesh 


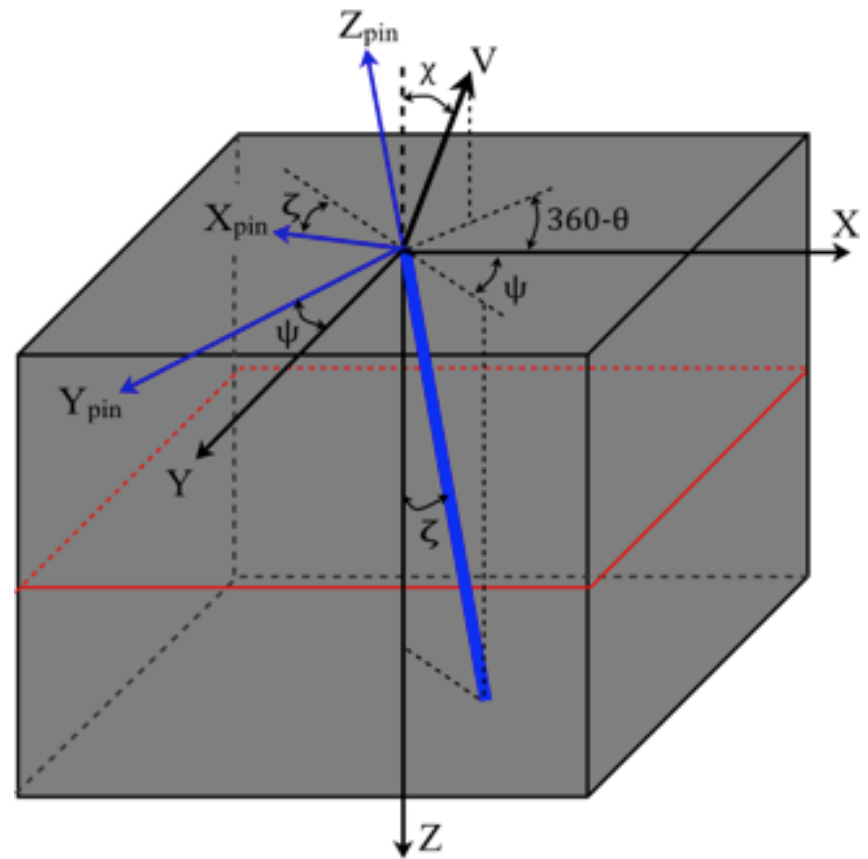

Fig. 5. Z-pin misalignment description.

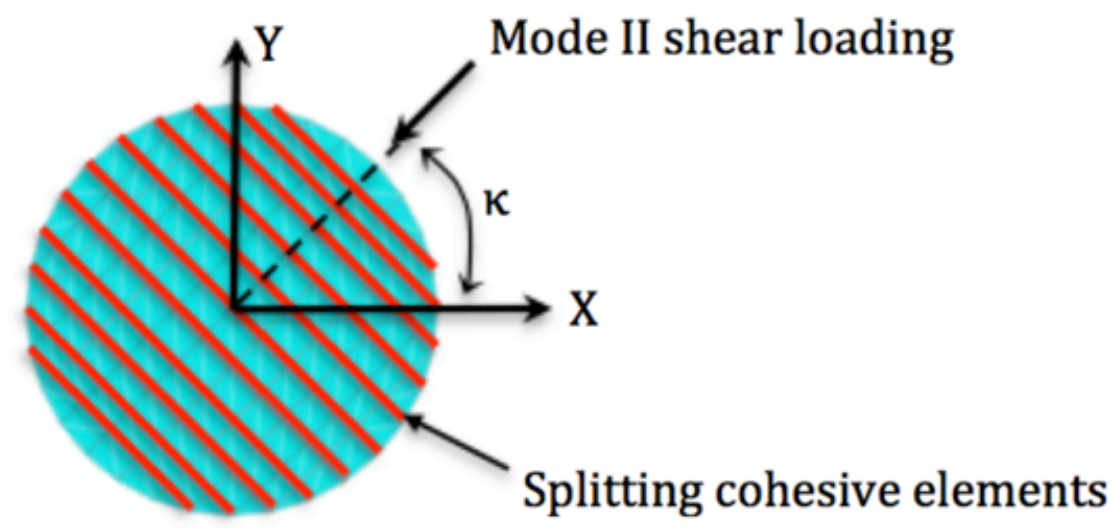

Fig. 6. Z-pin mesh with splitting layers. 


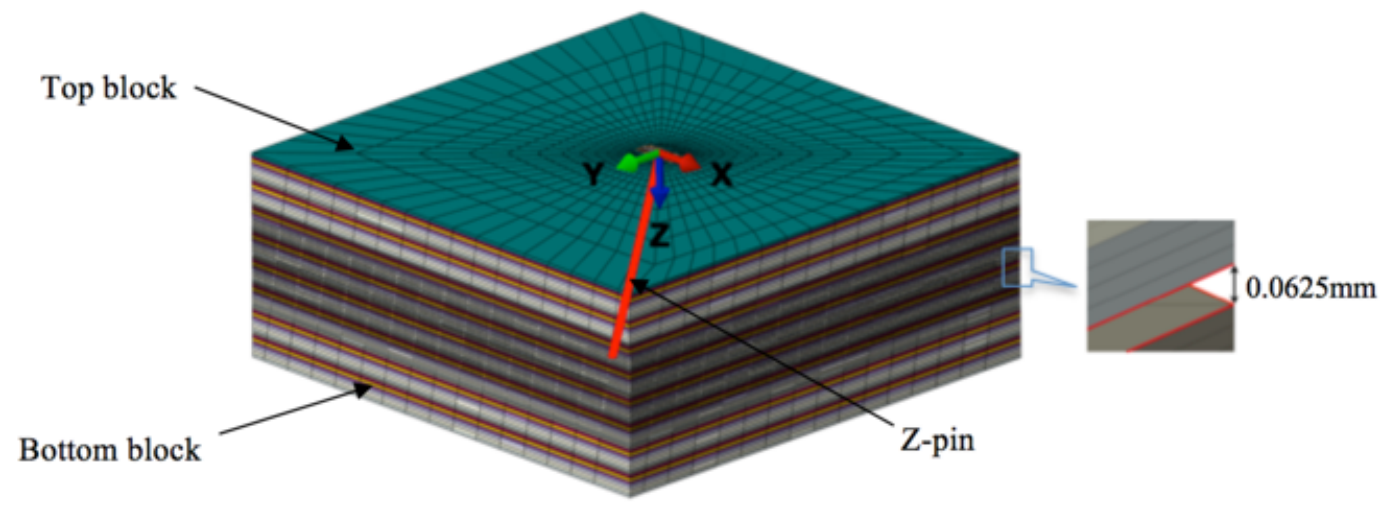

Fig. 7. Full FE mesh of Z-pinned laminate

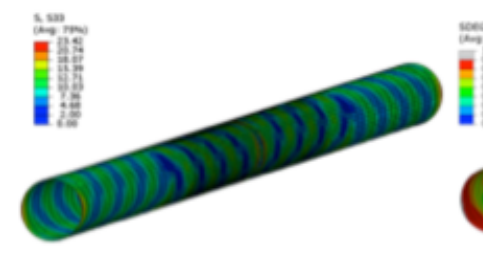

(a)

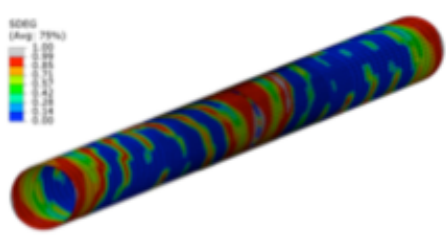

(b)

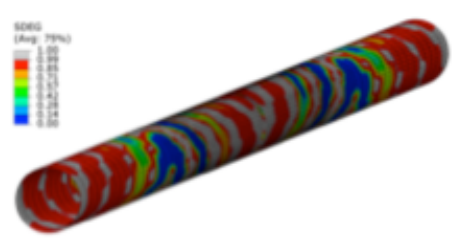

(c)

Fig. 8. Interface condition at (a) $-50^{\circ} \mathrm{C}$ cool down described by radial stress $\mathrm{S} 33$; (b) $-100^{\circ} \mathrm{C}$ and (c) $160^{\circ} \mathrm{C}$ described by element failure indicator. 




(a)

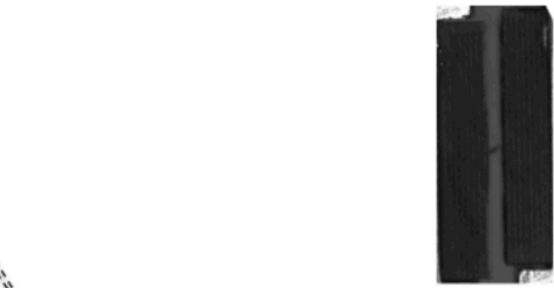

(b)

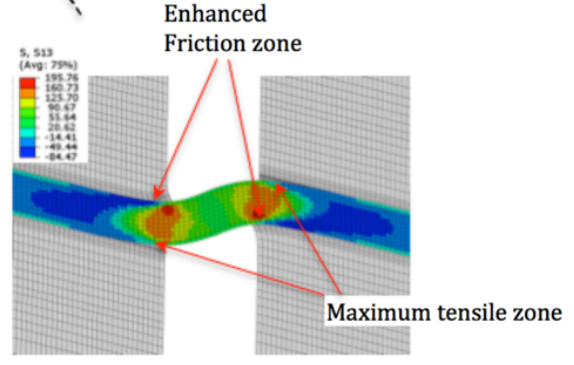

(c)

Fig. 9. Snapshots of Z-pin bridging mechanism in the mixed-mode loading captured in (a) FE model and (b) experiment; and (c) Z-pin deformation.
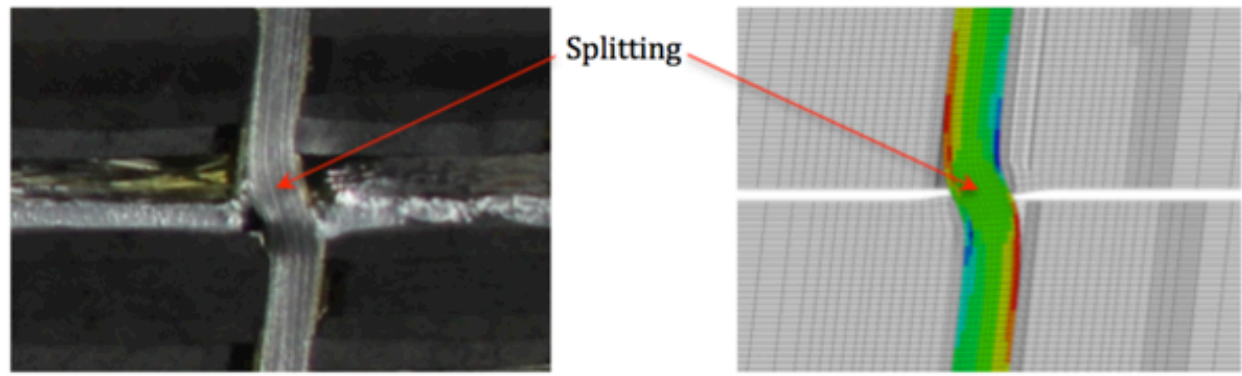

(a)
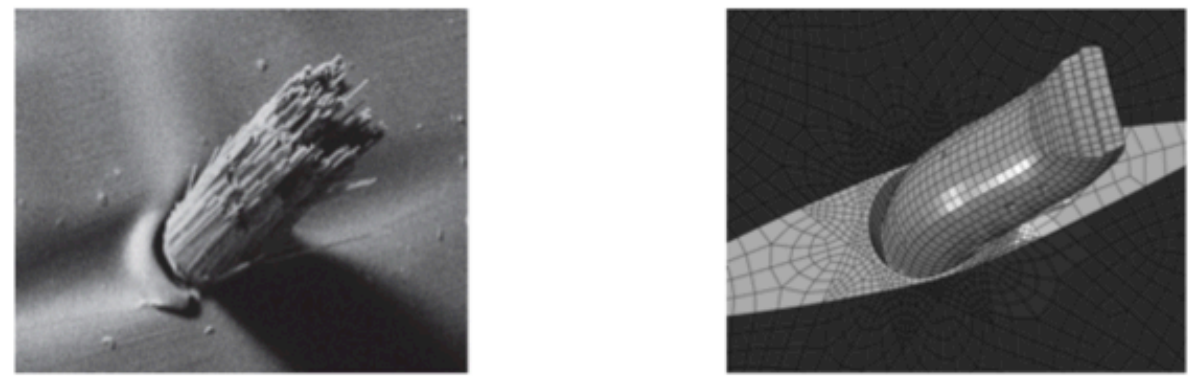

(b)

Fig. 10. (a) Z-pin splitting and (b) complete rupture observed in experiments and FE models. 


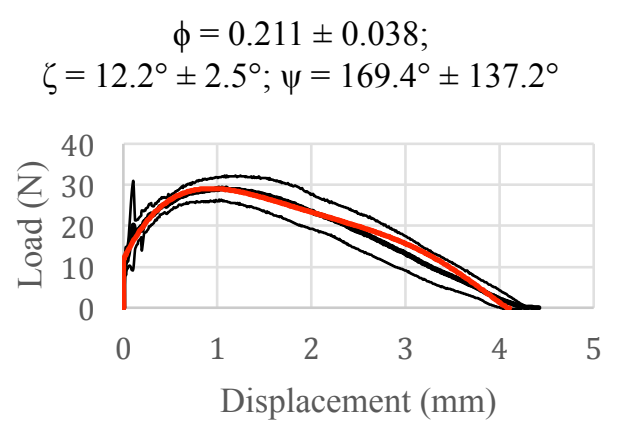

(a) 5 specimens tested



(c) 5 specimens tested



(e) 3 specimens tested

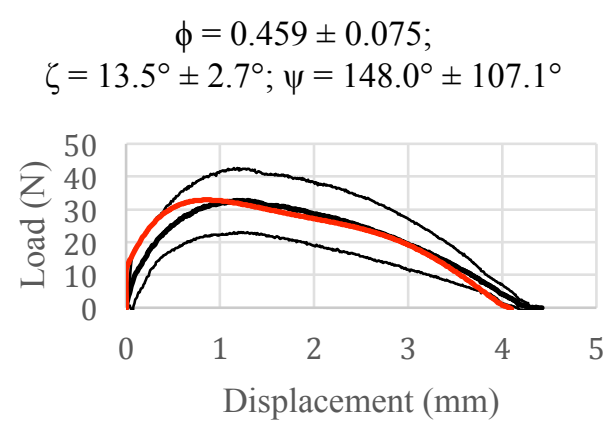

(b) 5 specimens tested

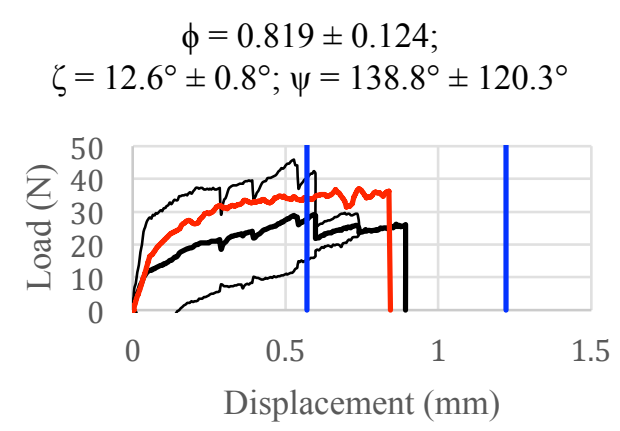

(d) 4 specimens tested

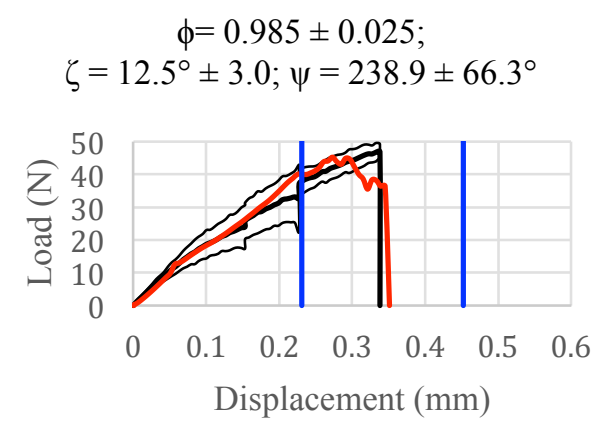

(f) 6 specimens tested

Fig. 11. Comparison between load-displacement curves of FE models and experiments; average experimental load in thick black lines; FE load in thick red lines; thin black lines indicating experimental load bands defined by mean load plus/minus one standard deviation; blue vertical lines indicating rupture displacement bands defined by mean plus/minus one standard deviation. 


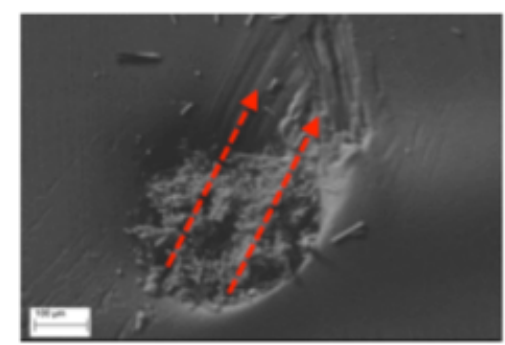

(a)

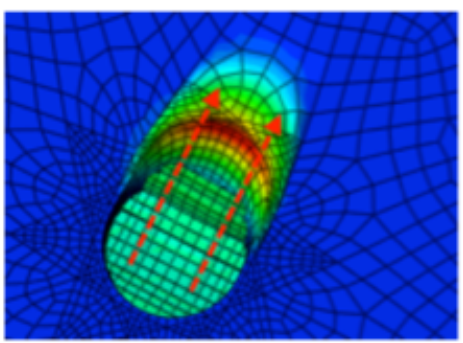

(b)

Fig. 12. Failure mode of Z-pins under 0.985 mixed-mode loadings in (a) experiment and (b) FE models.

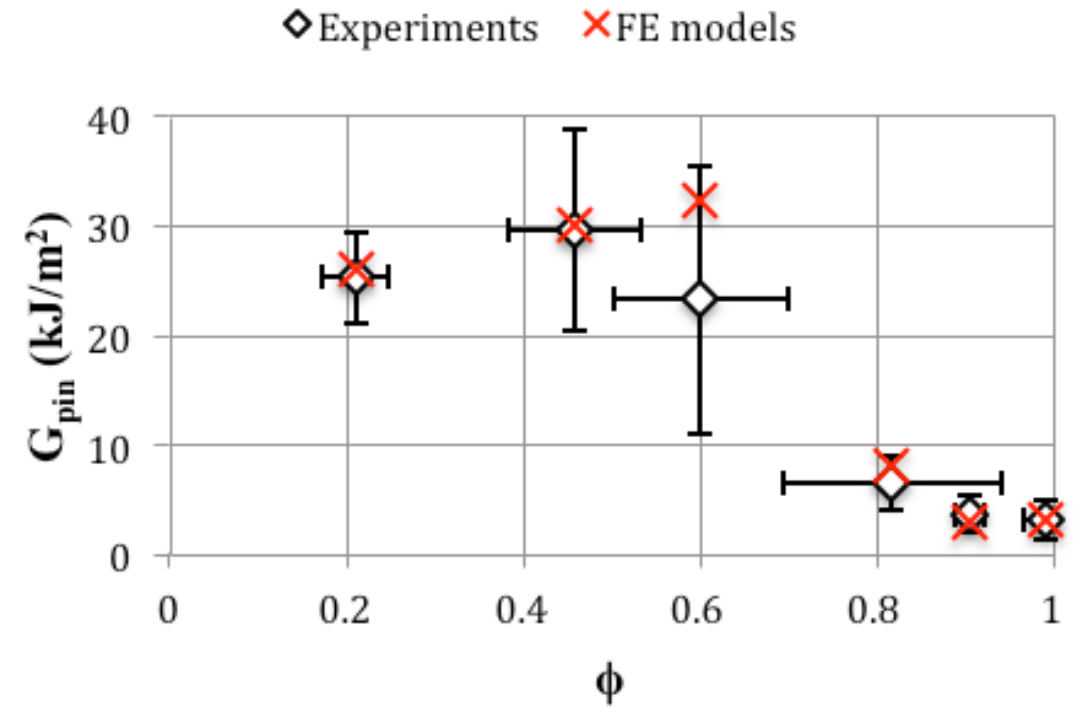

Fig. 13. Comparison of bridging toughness between FE models and experiments. 

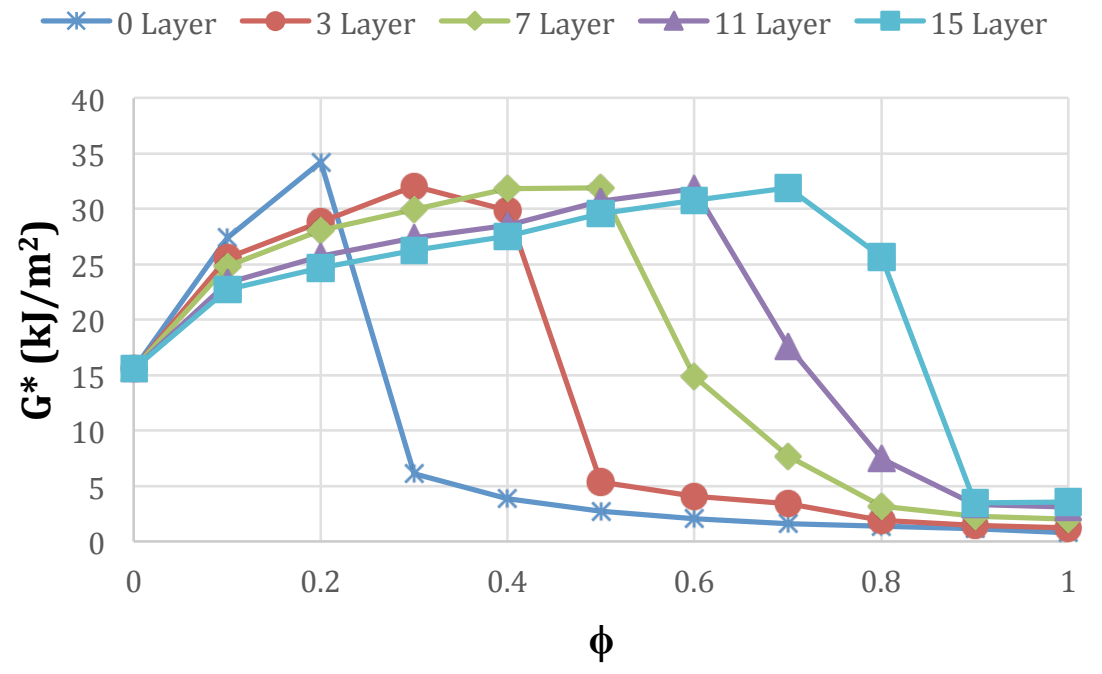

Fig. 14. The effect of splitting density on the apparent fracture toughness.

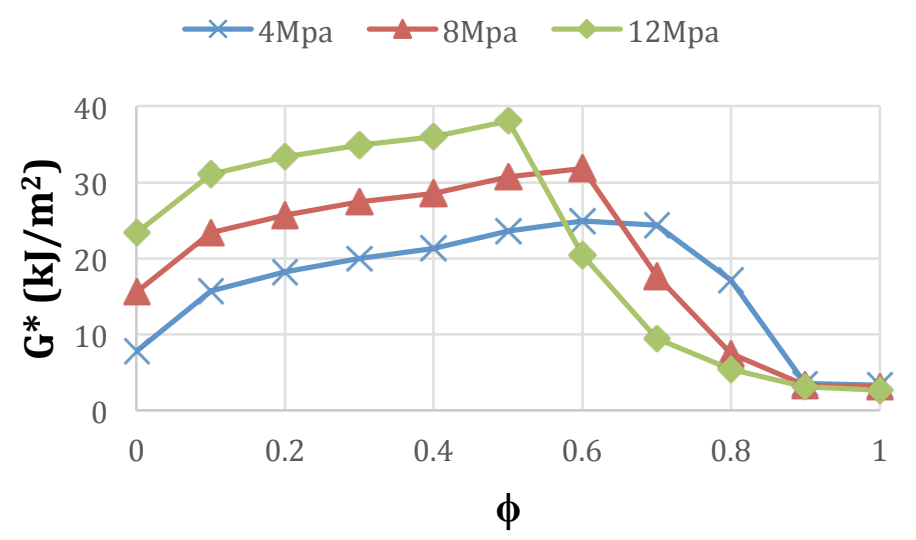

Fig. 15. Effect of residual friction stress on apparent fracture toughness. 


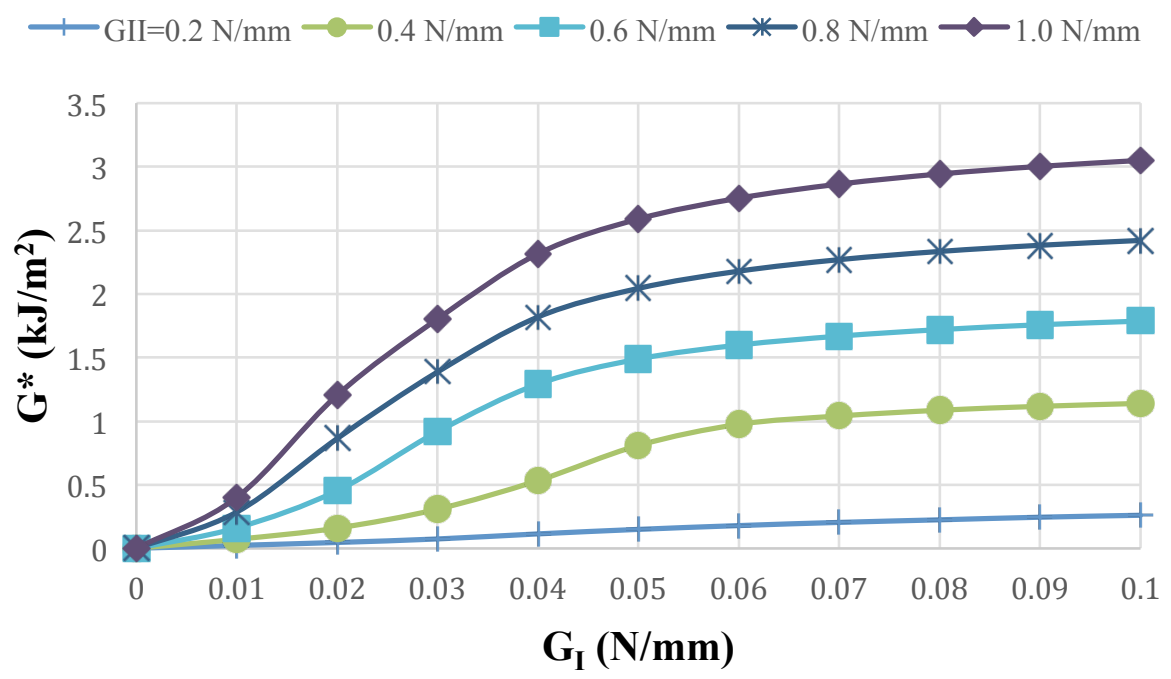

Fig. 16. Effects of $\mathrm{G}_{\mathrm{I}}$ and $\mathrm{G}_{\mathrm{II}}$ of the Z-pin/laminate interface on the apparent fracture toughness under pure Mode I pull-out.

\begin{tabular}{|c|c|c|c|c|c|}
\hline $\mathrm{W}(\mathrm{mm})$ & $\mathrm{L}(\mathrm{mm})$ & $\mathrm{b}(\mathrm{mm})$ & $\theta_{\max }\left({ }^{\circ}\right)$ & $\alpha$ & $\mathrm{D}(\mathrm{mm})$ \\
\hline 0.8 & 2 & 0.15 & 8.5 & 1.5 & 0.28 \\
\hline
\end{tabular}

Table 1. Parameters of ply-level mesh. 


\begin{tabular}{|l|c|c|c|}
\hline & $\begin{array}{c}\text { Laminate } \\
(\mathrm{IM} 7 / 8852)\end{array}$ & $\begin{array}{c}\text { Z-pin } \\
(\mathrm{T} 300 / \mathrm{BMI})\end{array}$ & $\begin{array}{c}\text { Resin } \\
(8552)\end{array}$ \\
\hline Young modulus, $\mathrm{E}_{\mathrm{x}}(\mathrm{GPa})$ & 161 & 144 & 4.57 \\
\hline Young modulus, $\mathrm{E}_{\mathrm{z}}(\mathrm{GPa})$ & 11.38 & 7.31 & 4.57 \\
\hline Shear modulus, $\mathrm{G}_{\mathrm{xz}}(\mathrm{GPa})$ & 5.17 & 4.45 & 1.67 \\
\hline Shear modulus, $\mathrm{G}_{\mathrm{yz}}(\mathrm{GPa})$ & 3.98 & 2.63 & 1.67 \\
\hline Poisson's ratio, $\mathrm{v}_{\mathrm{xz}}$ & 0.32 & 0.25 & 0.37 \\
\hline Poisson's ratio, $\mathrm{v}_{\mathrm{yz}}$ & 0.436 & 0.39 & 0.37 \\
\hline Thermal coefficient, $\alpha_{\mathrm{zz}}\left({ }^{\circ} \mathrm{C}^{-1}\right)$ & $3 \mathrm{e}^{-5}$ & $3.0 \mathrm{e}^{-5}$ & $6.5 \mathrm{e}^{-5}$ \\
\hline Thermal coefficient, $\alpha_{\mathrm{xx}}\left({ }^{\circ} \mathrm{C}^{-1}\right)$ & 0 & 0 & $6.5 \mathrm{e}^{-5}$ \\
\hline
\end{tabular}

Table 2. Material properties of laminate, Z-pin and resin defined in the local coordinate system x-y-z of each ply.

\begin{tabular}{|l|c|c|c|c|c|c|c|c|c|c|}
\hline & $\begin{array}{c}\sigma_{\mathrm{I}, \max } \\
(\mathrm{MPa})\end{array}$ & $\begin{array}{c}\sigma_{\mathrm{II} \max } \\
(\mathrm{MPa})\end{array}$ & $\begin{array}{c}\mathrm{K}_{\mathrm{I}} \\
(\mathrm{N} / \mathrm{mm} 3)\end{array}$ & $\begin{array}{c}\mathrm{K}_{\mathrm{II}} \\
(\mathrm{N} / \mathrm{mm} 3)\end{array}$ & $\begin{array}{c}\mathrm{G}_{\mathrm{IC}} \\
(\mathrm{N} / \mathrm{mm})\end{array}$ & $\begin{array}{c}\mathrm{G}_{\mathrm{IIC}} \\
(\mathrm{N} / \mathrm{mm})\end{array}$ & $\beta$ & $\mu$ & $\begin{array}{c}\tau_{0} \\
(\mathrm{MPa})\end{array}$ & $\begin{array}{c}\tau_{\max } \\
(\mathrm{MPa})\end{array}$ \\
\hline $\begin{array}{l}\text { Z-pin/laminate } \\
\text { interface }\end{array}$ & 60 & 90 & $1.0 \mathrm{e}^{5}$ & $1.0 \mathrm{e}^{5}$ & 0.01 & 1.0 & 1 & 0.8 & 8.0 & 90 \\
\hline Z-pin split & 60 & 90 & $1.0 \mathrm{e}^{5}$ & $1.0 \mathrm{e}^{5}$ & 0.2 & 1.0 & 1 & 1.05 & 0 & 300 \\
\hline
\end{tabular}

Table 3. Modelling parameters of Z-pin splitting and Z-pin/Laminate interface. 